\title{
IDENTIFICATION OF THE MAIN ASPECTS OF COOPERATION MANAGEMENT AND THE PROBLEMS ARISING FROM THEIR MISUNDERSTANDING
}

Goal of the article is to identify main aspects of cooperation management, using detailed analysis of available scientific literature together with outcomes of performed empirical research. With the identified main aspects, we were able to identify problematic areas related to the use of cooperation management and to propose a number of recommendations in order to correct these issues. The article thus brings to managers a handy tool in a form of a set of recommendations (instructions) that are meant to support problem-free use of cooperation management within a company.

Keywords: Cooperation management, project management, strategic management, change management, process management, management of human resources.

\section{Introduction}

The hurdle of building cooperation management within a company is a real challenge that managers of companies often face. The process of building cooperation management involves a number of factors, ranging from theoretical concepts all the way to practical applications. At present, companies often strive to manage their cooperation initiatives intuitively. There are several unsuccessful activities in the area of implementation of cooperation management that can be identified among real-life companies. The reason for these failures can be chiefly attributed to missing clear plan of activities, division of competencies for implementation and, last but not least, company strategy oriented towards creation and development of cooperation. Errors are also made by managers, mainly due to misunderstanding of the term cooperation management and underutilization of cooperation potential of a company.

Company management represents the main link on the connecting line between the company and its partners. It has multiple tools at its disposal and its managers can use these tools for implementing cooperation management in the company. For this reason it is important that the company possesses knowledge about the main aspects of cooperation management and using suitable managerial approaches ensures durability of relations between the partners within cooperation [1,2 and 3].

\section{Objective and methodology}

The main goal of the article is to collect novel information and knowledge in the area of cooperation management, specifically focusing on defining cooperation management within the area of management, and to highlight managerial tools and techniques available for use in cooperation management in a company. Identification of the main aspects of cooperation management could significantly help with the search for problematic areas related to cooperation management. These areas require additional attention of the company and represent room for further development and improvement. Subsequent recommendations are meant as practical tools in a toolkit of company managers, ready to be used during implementation of cooperation management of the company.

In order to address the points in question, as set by this article, it was necessary to use several methods, depending on and fitting to the character of the individual parts of the solution. In order to accumulate necessary data, we used the method of document analysis (for analysis of current as well as historical data about the topic), a questionnaire method and a method of semi-structured interview (gathering data in an empirical research) and a method of observation (used during visits of selected companies).

For processing the data, we mainly used a method of quantitative evaluation (statistical methods and tools were applied) and a method of comparison (for comparing data

\footnotetext{
* Josef Vodak, Jakub Soviar, Viliam Lendel

Department of Management Theories, Faculty of Management Science and Informatics, University of Zilina, Slovakia

E-mail: jakub.soviar@fri.uniza.sk
} 
gathered by empirical research and data from the analysis of secondary information sources).

The performed research focused on medium and large enterprises active in the Slovak Republic. The respondents were company managers on the mid to top management level within the managerial hierarchy of companies. In total, 221 respondents took part in the research focused on diagnostics of the level of use of cooperation management.

Research included companies active in multiple sectors of the Slovak economy. Companies included were categorized by the Statistical Office of the Slovak Republic as medium or large enterprises. The respondents were company managers on the mid to top management level within the managerial hierarchy of companies. Size of the sample was 345 respondents, with the required $95 \%$ interval of reliability and the maximum allowable error of 5\%. Since 221 respondents actually took part in the research, the maximum allowable error reached 6.37\%. Data was gathered exclusively via personal interview.

The following methods were used for approaching and solving the research goals: induction, deduction, synthesis (identification of the main aspects of the cooperation management, formulating recommendations for minimal chance of problems), abstraction and model building.

\section{The current state of dealing with the issue}

We identified an ongoing scientific discussion regarding the term cooperation management, its definition and the scope of use. Several definitions of cooperation management can be found in the scientific literature, however, these typically address only a subset of the whole task of cooperation management. High variability in interpretation of the term can be supported by the following examples. Lafleur (2005) understands cooperation management as a way of managing and developing collaboration in a competitive environment [4]. According to Ray (2002), cooperation management represents a term for integrated management of company networks [5]. Staatz (1983) sees cooperation management as cooperative decision making within heterogeneous preferences [6]. He highlights the need for a model of cooperation based on a defined group choice.

Similar view is held by Watzlawick, whose idea of cooperation management is that of a complex decision making process, ongoing on three levels of the managerial pyramid, whose goal is to reach suitable balance between company success within cooperation as a business unit and as a social institution. Mendoza sees cooperation management as an effective use of resources within cooperation as a business organization, focused on satisfying needs of its members, according to the accepted cooperation principles. Zhang (2011) believes that cooperation management represents a basis for solving all managerial problems [7]. According to him, cooperation management provides conditions for creating a system of cooperation based on effective use of resources and technologies. Veerakumaran (2006) summarized the most important characteristics of cooperation management into the following points [8]:

- Cooperation management is a complex decision making process and the decisions are made on all managerial levels.

- Primary goal of cooperation management is to satisfy the needs of the members of cooperation.

- All activities need to occur according to the agreed principles of management and cooperation.

- Suitable balance needs to be established between the efforts for commercial success and maintaining goals of the cooperating parties.

- Management focused on reaching a goal via effective use of resources.

A more detailed definition of the term cooperation management requires that the management as such is first defined, both as a science and as a practical activity. Consequently, a large number of possible definitions are available. Let us list three definitions that suitably capture the meaning of management.

Coulter and Robbins define management as "a process of coordinating work activities of people in such a way that the activities are performed efficiently" [9]. Here, the "process" represents the main managerial functions: planning, organizing, leadership and control. "Coordination" represents the attribute that differentiates managerial positions from the non-managerial ones, i.e. the position in the hierarchy of power. "Efficiency" means to conceptually achieve better (larger, richer) outputs that inputs. Efficiency in this sense is to be closely connected with effectiveness and the meaning to achieve the set goals.

Authors of US background Koontz and Weihrich offer the following definition: "management is a process of creating and maintaining certain environment, in which individuals work in groups and effectively/efficiently achieve the set goals" [10].

From the local environment, we selected the following complex definition: "management is a process where managerial employees use scientific knowledge as well as practical recommendations and are able to perform elementary managerial activities in the process of appraising disposable resources, with the goal to determine and achieve company business goals." [11].

The listed definitions define the main role of management within an organization. No organization exists just by itself, isolated. Every organization is a part of a broader system. Parts of these systems influence each other to a higher or lower degree, and their mutual influence and impact determines their survival on the market. Logically, role of management needs to be focused on the market success of a commercial organization, or more generally, success of an organization in its environment.

Relationships exist between companies, customers, suppliers, elements of distribution networks etc., that represent separate corporate units, exist and it is necessary to manage them. Managing relationships in social organizational units, or between 
them, is always based on the use of management. Managing relationships between separate organizations could be labeled as cooperation management. Based on that, we are able to supply a more precise definition:

Cooperation management is effective and efficient management of relationships in a cooperation between separate and relatively independent organizations or individuals, with the goal of improving their competitiveness [12 and 13].

\section{Situation in Slovak enterprises - results of the empirical research}

Between September 2012 and February 2013 we conducted a research, with the primary goal to gather and interpret information about the level of use of cooperation in the environment of Slovak enterprises. The main goal of the research was to identify the key aspects of efficient management and functioning of cooperation, related issues, degree of satisfaction of companies within cooperation and the opportunities for improvement of already functioning cooperation. Data that was gathered provided complete picture about readiness of Slovak enterprises to use (implement) cooperation management. In total, 273 managers of small, medium and large enterprises took part in the research, from companies active in the Slovak Republic. Data from the respondents was gathered via personal interviews.

Currently, Slovak enterprises have developed cooperation mainly in the form of supplier relationships (68.13\%), purchasing relationships (52.38\%), technical cooperation (44.32\%), education (35.16\%), advertising and promotion $(24.18 \%)$. On the contrary, Slovak companies cooperate least in the areas of media (9.52\%), financial consulting (10.99\%), ecology (10.99\%), management (11.36\%) and investments (11.72\%).

It could be considered positive that almost half of the respondents $(47.62 \%)$ plans in the near future (within one year) to establish a more intense cooperation with a company or an organization. Less than $17.22 \%$ of the companies represented in the research do not plan to establish any cooperation in the near future and $35.16 \%$ of respondents were unable to respond.

Some of the most preferred areas of interest for a more intense cooperation in the near future were the following:

- Purchasing of products and services (59.23\%),

- $\quad$ Supplying of products and services (57.69\%),

- Technical cooperation (43.08\%),

Technical consulting (25.38\%),

Advertising, promotion (23.08\%).

The main challenges and problems that were listed by respondents to occur in the process of cooperating with companies and organizations were mainly insufficient adherence to the agreed contractual terms (58.39\%), financially demanding (35.04\%), distortion of information (34.41\%), low effectiveness of cooperation $(29.56 \%)$, unwillingness to provide internal information by a cooperating company, i.e. concerns about providing internal information to a company (28.83\%) (Fig. 1).

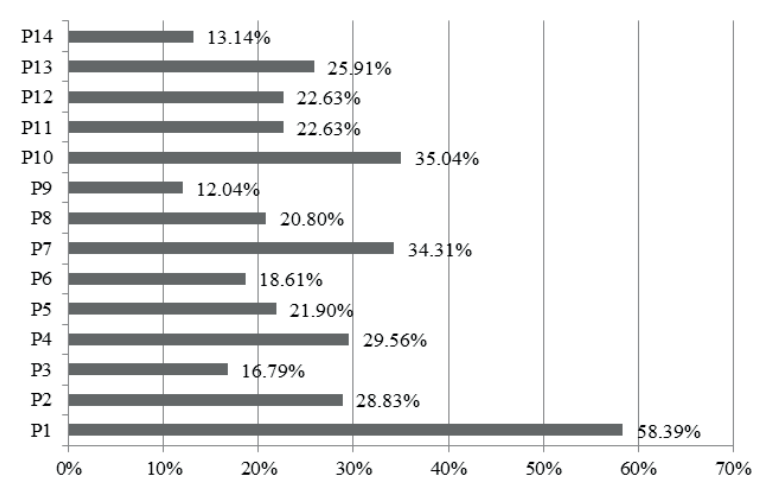

Legend:

P1 Insufficient adherence to the contractual terms of the cooperation

P2 Unwillingness to provide internal information (concerns to provide internal information)

P3 Unwillingness to cooperate of the cooperating company (partner)

P4 Low effectiveness of the cooperation, i.e. costs are always larger than the resulting outcomes

P5 Insufficient harmonization and interconnectedness of the partners IT systems

P6 Unwillingness to communicate with the partner

P7 Distortion of information (incorrect, insufficient etc.)

P8 Limited willingness of employees to maintain and develop cooperation (negative attitude to cooperation)

P9 Limited willingness of management to cooperate

P10 Financially demanding

P11 Lack of time availability of management

P12 Questionable quality of cooperation (uncertain added value)

P13 Results do not correspond to the effort put into cooperation

P14 Lack of trust towards the cooperating company

Fig. 1 Problems arising during cooperation with companies and organizations

Source: Own research

Using the realized research we also identified the main advantages of cooperation of the included companies with their partners (other companies, organizations etc.). Based on the number of responses we constructed the following order of the most advantageous impacts of cooperation, as perceived by the companies ( 1 - the most frequently seen and mentioned advantage of cooperation):

1. Supplier-purchaser relationships - perceived advantage in a form of better, safer and more reliable mutual cooperation, service options, infrastructure and specialized legal services, expansion of the portfolio of clients, time flexibility, regular and timely supplies, responsibility, trust, adherence to 
contractual terms, speed of dealing with complaints, good logistical relationships;

2. Communication - perceived advantage in a form of information about new products, consulting services, willingness to deal with problematic situations, willingness to take part on meetings, supply information via information system of a company, high degree of openness in internal communication within the organization;

3. Finance - perceived advantage in a form of lower costs, improved bottom line, higher profits, opportunity to offer products for better prices, increased turnover and sales, increased number of resources and improved payment abilities of the companies;

4. Competitive advantage - perceived advantage in a form of marketing, brand building, name and image, improved position on the market, improved technical capabilities, use of innovations and novel technologies, expansion of product portfolio, improved access to products, sharing of know-how, improved efficiency of manufacturing, improved quality of products and the value for customers;

5. Education - perceived advantage in a form of available information and knowledge about cooperation, experience, supplying of results, teaching of graduates, securing qualified workforce, continuous education of employees and students in new areas, higher degree of expertise;

6. Internal environment - perceived advantage in a form of employee motivation, development of the company, location of company branches, office interior, possibility to shorten the hiring process;

7. Projects - perceived advantage in a form of collaboration on preparing, submitting and performing projects, expanded portfolio of projects, securing higher number of larger contracts and orders.

\section{Identification of the main aspects of cooperation management}

Management represents the main element on the connecting line between a company and its partners. In order to work, management requires information from the IT system, mainly information accumulated by the departments involved in the cooperation. It has at its disposal multiple tools that ensure speed of communication between partners and removal of unnecessary contacting of departments in order to obtain basic information. Thus it supports satisfaction of the partners, makes their work more effective and saves time for all people involved.

A mutual connection exists between management and cooperation management. Cooperation management offers immediate overview about the overall development of the key areas of the business as well as a perspective on individual cooperation activities performed by employees. Management manifests within cooperation management mainly through the following elements (Fig. 2):

- strategic management,

- change management,

- project management,

- process management,

- management of human resources.

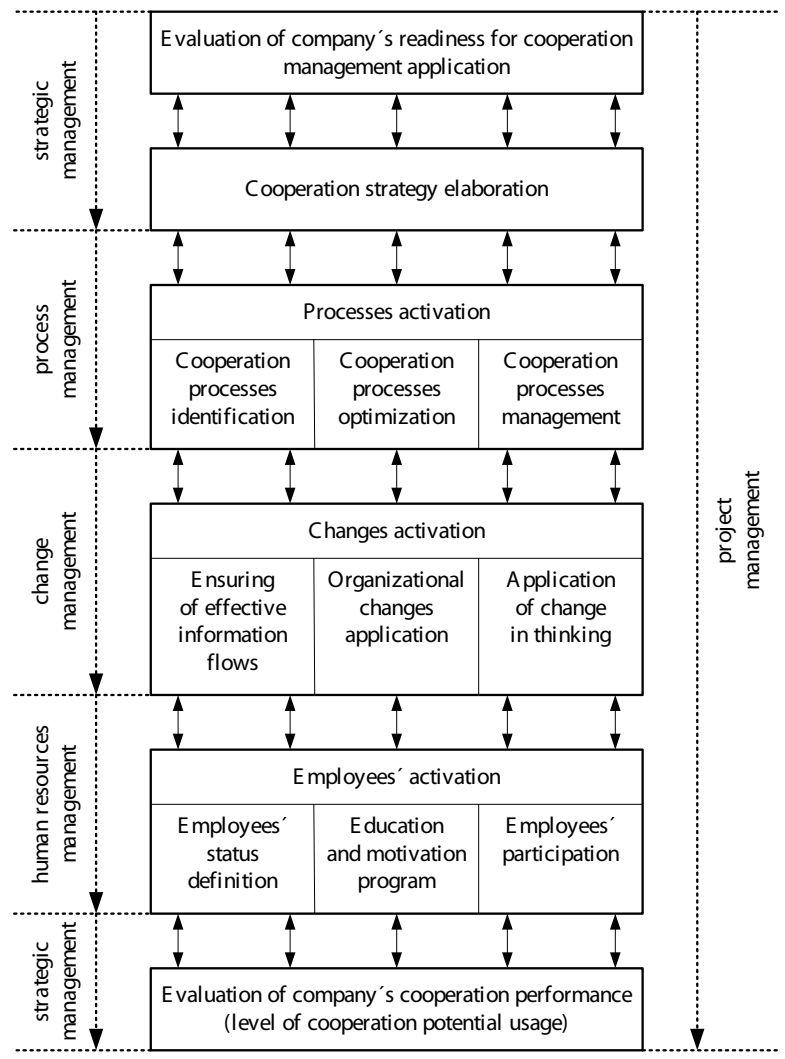

Fig. 2 Identification of the main aspects of cooperation management Source: Own elaboration

\section{Strategic management and cooperation management}

Strategic management is used in the area of cooperation management mainly for formulating cooperation strategy which is preceded by a detailed analysis of current situation within the company. Process of establishing cooperation strategy according to Child et al. (2005) involves effort of the company to realize its goals using cooperation with other organizations [14]. The concept of strategy in relation to cooperation was well grasped by Faulkner (1995). His definition highlights the essence of cooperation relationships [15]. According to him, cooperation strategy represents a process of searching for reasons to establish cooperation, selection of suitable partners whose goals are compatible with the goals of the company, and a process of integration of partner cultures and systems. 
Phoocharoon et al. (2001) emphasize that the role of cooperation management is not to create a company strategy [16]. Quite the contrary, it is about understanding that is needed in order to create a suitable cooperation strategy. Similarly, the company should suggest how this strategy should develop over time. It is important that the cooperation strategy is linked to and supports the company strategy. The latter stems from the mission and the purpose of the company. It helps company management to correctly direct the business and to prepare for unavoidable changes and risks of various character [17]. In the process of creating cooperation strategy, it is important to define the method of solving conflicts, to alight strategic goals of partners and to establish strategic cooperation connection based on integration of the used cooperation channels. He also considers cooperation strategy to be a method for improving performance of the involved parties, with the goal of achieving strategic competitiveness. In order for this to happen, it is needed to bring in strategic thinking, characterized by continuous analysis of the environment, readiness for change, integration, concentration of cooperation resources and continuous learning. Multiple methods of strategic management are used for performing the analysis of current situation within as well as outside of the company (e.g. in regional environment [18], etc.).

\section{Change management and cooperation management}

Change management is used in cooperation management mainly after evaluating readiness of a company to enter into cooperation and after making a decision to move to either new or expanded cooperation initiatives. In such situation it is good for the company to approach key cooperation processes in a structured and integrated manner. Most frequently, the involved initiatives are as follows:

- Higher effectiveness in using human resources,

- Support of new innovation projects, research and development,

- Joint realization of marketing activities,

- Improved quality of mutual communication, networking. Once the company defines each of the key cooperation processes, such as development of cooperation strategy, establishing strategic connection, integration of communication channels, management of information and performance evaluation, it needs to consider consequences of making changes in any of the processes. In order to implement extensive and complex cooperation initiatives, the company will need to undergo organizational and cultural changes. The decisive aspect in all this will, therefore, be the use of effective change management in the company.

Change management is primarily concerned by people, systems and organizational changes. The 7-S model developed by strategic consultants McKinsey \& Company offers a strong tool for planning initiatives within change management in relation to cooperation management. The model consists of seven basic elements: Strategy, Structure, Systems of management, Style of management, Staff, Skills and Shared values. Apart from the traditional aspects of changes such as strategy, structure and systems of management, the model emphasizes that companies should consider also additional four elements, i.e. style of management, staff, skills and shared values, in order to be successful in their change management initiatives [19]. This model can aid companies to efficiently manage changes by carefully managing and organizing relevant components of each element. This means that cooperation strategy needs to be embraced by employees with certain skills, shared values within the organizational culture, systems, style of management and organizational structures.

Changes needed as a result of implementing cooperation management in a company are clearly important. A number of potential barriers exist that may prevent such change, e.g. deeply rooted interest to maintain status quo. Therefore, in order to succeed in implementing cooperation management, it is essential to understand and act based on the requirements of change management.

\section{Project management and cooperation management}

Importance of project management increases as the cooperation initiatives gets larger and more complex. Projects are a specific set of activities that were designed in such a way that they need to achieve set goals within a certain time interval. Successful cooperation projects are based on cooperation goals that are derived from the company goals. They should also support and complement the overall company strategy. Efficient company management plays a crucial role in implementing cooperation management in a company. History tells us that projects that exceeded budget as well as the set time interval can result in considerable losses.

It is important that top management and heads of cooperation projects understand the role of information technologies in realization of cooperation management. There are several reasons for using information technologies to manage cooperation: ensuring efficiency of information flows, reduction of costs, improved communication with partners and ensuring coordination of individual cooperation activities. In case a proposed investment into information technologies that would be used to manage cooperation is valid and justified, it is reasonable to review it properly in this context.

Payne (2005) emphasizes that project management uses not only methods focused on controlling time and resources but also uses and improves a number of usual methods typically used in general management, e.g. teamwork, orientation process and leadership [20]. Currently, the field of project management has been expanded by sophisticated methods of management and control of time, costs, resources, quality and performance. 


\section{Process management and cooperation management}

Basis for functioning of any company are its processes. Process management is established on the principle of activity integration into comprehensive processes. The process approach is based on the assumption that the causes of unacceptable economic results are poorly set cooperation processes. For this reason it is necessary to make all cooperation processes more efficient and to eliminate those that do not bring the desired outcomes.

The main goal of process management in relation to cooperation management in a company is the effectiveness of cooperation processes. Process management takes a comprehensive view of all company activities and integrates them into individual processes. Information exists and is available for each activity, e.g. who is realizing the activity how is the realization going, in what way, what are the limitations for realization, what is the input for the activity, what are the outputs, relationship of the internal customers, spread of overhead costs to individual activities within the process. Every activity has a defined metric of performance. Another strong point for process management is implementation of any changes resulting from realization of cooperation initiatives in the process of managing a company.

Key requirement for successful use of cooperation management in a company is thorough mapping of current company processes. Attention should be specifically paid particularly to cooperation processes. It is necessary that they are identified and consequently optimized.

Management of human resources and cooperation management

A key role in cooperation management is definitely played by people, the employees of the company. The success of cooperation initiatives will depend on their performance and attitude. Unqualified employees may disrupt interests of the company within the established cooperation. According to Blaskova (2003), people within the company and their potential represent an effective and strategic competitive advantage [21]. People and their motivation, knowledge, skills, capabilities, creativity and flexibility become the most important strategic resource for successful realization of cooperation initiatives in a company. Employees prepare analysis of the situation, together with the management they set cooperation goals, formulate cooperation strategy, action plans as well as a system for control of effectiveness and efficiency of cooperation initiatives. In short, employees play a crucial role in using cooperation management in a company. By using a suitable motivation program, ensuring possibility for further education and establishing suitable work environment can company achieve smooth implementation and use of cooperation management and eventually successful realization of cooperation initiatives.

\section{Discussion}

Use of cooperation management in a company is a complex process that requires thorough understanding of the company environment. Company managers should be aware that implementation of cooperation management also brings certain risks. Otherwise would this initiative be doomed to failure. In order to succeed in this area, it is a key to identify risk areas early and to take corresponding measures in order to increase probability of success of implementing cooperation management in a company.

In the next part we identify possible risks together with recommendations that are meant to help to reduce these risks. A necessary requirement for successful functioning of cooperation management in a company is also prevention.

The most frequent issue is underutilization of cooperation potential of a company. The company either is not aware of its cooperation potential or the suitable conditions for its development and use are not present. Manifestations of this issue differ. Chiefly they are represented by arising misunderstanding, costs, realization of inefficient cooperation processes (often repeated multiple times).

Managers of a company should dedicate their time to thorough analysis of cooperation capacity of the company. Company needs to possess suitable overview about its knowledge, experience, resources, assets and managerial skills and capabilities that are available and could be fully used in order to create and manage cooperation. However, this requires that the top management of a company had a clear idea about building and managing cooperation. This needs to be reflected in company strategy, supported by corresponding human and financial resources. Managers need to actively communicate with potential partners as well as own employees and to engage them in establishing of cooperation. It could also be recommended to the top management team that a motivation program is created, with the aim to stimulate employees to engage into cooperation processes. Employees represent a key aspect for success of cooperation management.

Another risk area is the absence of information system that would support efficient exchange of information between partners within cooperation. Information from the partners is often not registered in a form in which it could later be used or is not accessible to all relevant persons. This leads to situations when managers and employees do not react sufficiently to information responses in cooperation.

Managers of a company should also consider creating corresponding databases interconnected with company information systems. Every person in a company should know how to react in case of a relevant impulse. This can be enabled only by effective work with information as part of the cooperation. Information system needs to reflect the requirements 
and current situation in the area of information technologies of the cooperating partners.

Another serious issue is missing necessary environment that would support establishing of cooperation - suitable culture. Managers of a company should consider focusing on establishing a company culture based on communication and collaboration. In addition to the already mentioned recommendations, implementation of which could improve quality of the cooperation environment, it is necessary to focus even further on employees of the company. Top management of the company should strive to stimulate employee activities by creating suitable environment that would ensure open communication, discussion about cooperation opportunities and work in teams. Managers need to transfer their engagement to their team members and they consequently bring the engagement into the development of new cooperation.

Poorly prepared cooperation program represents a frequent issue for implementing cooperation management in a company. Company managers tend to focus only on the technology side of cooperation and forget the other dimensions. Company needs to have at its disposal sufficient amount of information about cooperation processes, cooperation abilities and cooperation resources. In case the company does not dedicate necessary attention to this area and begins to implement cooperation management based on an insufficient documentation, it is highly probable that such implementation effort is doomed to fail. Company managers should consider the following measures:

- Realize detailed analysis of current situation in a company,

- Correctly understand the role played by technology in implementation of cooperation management,

- Perform complex mapping of the potential for cooperation and specify the requirements placed on the cooperation,

- Correctly set a system for evaluating cooperation performance of a company, including its rules.

Problems can arise also in the process of defining cooperation goals that company aims to reach in relation to the planned cooperation. Frequently it is not clear in what way the cooperation will be implemented and the realization of which activities will be necessary. In such situation it is needed that the company understands the goals of its cooperation options and to reflect these into its strategic goals. Company managers should consider the following measures:

- Correctly understand the principles of cooperation (good knowledge of the topic, achieved by studying of the literature and other processional education),

- Clarify the situation where the company aims to get by using cooperation management,

- Understand the expected outcomes of cooperation and the ways that can lead to their achievement,

- Prepare common vision together with its partners.

An important problem is to exclude the human factor in the process of using cooperation management. Employees that do not participate in creating necessary documentation about the future cooperation, in the process of identification of cooperation potential and in setting the requirements of cooperation, would not have sufficient information about the goals of cooperation management. This can result in a situation where they perform certain activities without interest and passively, since they are not involved and informed about the company goals in this area. Managers could therefore consider the following in order to minimize this issue:

- Ensure regular communication with employees with the goal to create an environment suitable for building of future cooperation,

- Enable employees to take part in the development of cooperation program and consequently in using cooperation management in a company,

- Listen to and to consider ideas of employees about creating the cooperation program,

- Clarify to employees the meaning of cooperation for future direction of the company,

- Supply sufficient information to employees about every step in implementation of cooperation management in a company,

- Lead by example.

While securing cooperation processes there is a risk of automating the previously poorly set (wrong) processes. In order to minimize creation of this situation, managers could consider the following:

- Identify and regularly update cooperation processes,

- Place emphasis on the processes that are directly connected to work in the area of cooperation,

- Dedicate attention to analysis of current state of cooperation process,

- Create a separate process model of a realized cooperation. Use of cooperation management in a company can be successful only in case the company accepts the initial conditions that include certain limitations. In case of ignoring the initial conditions a number of serious issued arise. Managers could consider the following in order to prevent this from occurring:

- Define key indicators for use of cooperation management in a company,

- Define control points within the use of cooperation management in a company,

- Take into account limitations (degree of use of cooperation management, risk of failure, level of cooperation capacity etc.).

Only if measurable goals are defined the company management can consider and evaluate outcomes of cooperation. A frequent issue in the process of using cooperation management is the absence of feedback that is meant for those managing this process. It is necessary that the whole process of cooperation management (from the analysis all the way to realization) was monitored and evaluated.

Company management could therefore consider securing intermediate evaluation of use of cooperation management in 
a company. This requires that the goals of using cooperation management are clearly defined, based on measurable indicators. Company managers should clearly outline and set the metrics so that they could quickly and effectively manage company areas related to cooperation using well defined measurable goals. However it is necessary that the group of metrics be defined on the main priorities for managing cooperation activities of the company.

\section{Conclusions}

Managing of cooperation initiatives is closely related to management. Cooperation management provides valuable information that represents an input for strategic decision making. Cooperation management represents mainly a process that includes complete transformation of the company culture and its values. For this, it is necessary to apply principles of strategic management. Success in this area will depend on the company management and correct understanding of the real importance of cooperation management for the company. As long as the cooperation management is understood only as a technology and not as a behavior of the company towards its partners within the cooperation, then the whole project would be doomed to fail.

It is necessary to emphasize that people represent the single most important element of cooperation management
Use of suitable motivation tools, creating of suitable conditions and ensuring open communication between company top management and its employees will result not only in smooth course of individual cooperation activities but also in their continuous use in the future.

When using cooperation management, the area of process management definitely should not be underestimated. All cooperation processes within the company should be analyzed. Top management needs to see itself as the owner of all of the main processes and needs to be responsible for their quality and performance.

Important role in the process of using cooperation management in a company is represented by the top management. Specifically this includes pushing forward effective approaches, securing sufficient resources for all cooperation initiatives, finding valid arguments for change and establishing company rules that would ensure use of cooperation management within the company. This is an organizational change that needs to be managed in order to result in success. Therefore, change management and cooperation initiatives need to be closely interconnected.

\section{Acknowledgement}

This paper was partially supported by the Slovak scientific grant VEGA 1/0621/14 Marketing management in cooperative environment - Proposal of strategic cooperation management implementation model.

\section{References}

[1] VODAK, J., SOVIAR, J., LENDEL, V.: Identification of the Main Problems in Using Cooperative Management in Slovak Enterprises and the Proposal of Convenient Recommendations, Communications - Scientific Letters of the University of Zilina, vol. 15, No. 4, 2013. ISSN 1335-4205.

[2] PORTER, E. M.: Clusters and the New Economics of Competition, Harvard Business Review. Nov-Dec 1998, 25-26. ISSN 00178012.

[3] STOFKOVA, K., STOFKOVA, J.: Implementation of the Knowledge Management as a Competitive Advantage, EDULEARN10: Intern.conference on education and new learning technologies, Barcelona, 2010. Intern. Association of Technology, Education and Development (IATED), 2010, 001323-001328, ISBN 978-84-613-9386-2. 001323-001328.

[4] LAFLEUR, M.: A Model for Cooperative Challenges, Cooperative Grocer Network, No. 116, [online]: http://www. cooperativegrocer.coop/articles/2009-01-21/model-cooperative-challenges.

[5] RAY, P. K.: Cooperative Management of Enterprise Networks. Kluwer Academic Publishers, 2002. ISBN 0-306-46972-3.

[6] STAATZ, J. M.: The Cooperative as a Coalition: A Game-Theoretic Approach, American J. of Agricultural Economics, No. 5, vol. 65, 1983, 1084-1089.

[7] ZHANG, W.: Cooperation System Constructing and Model of its Operation Mechanism, Intern. Conference on Business Management and Electronic Information (BMEI), vol. 3, 2011, 784-787.

[8] VEERAKUMARAN, G.: COCM 511 - Management of Cooperatives and Legal Systems, Faculty of Dryland Agriculture and Natural Resources : Mekelle University, 2006.

[9] ROBBINS, P, S., COULTER, M.: Management, Grada : Prague, 2004. ISBN 80-247-0495-1.

[10] KOONTZ, H., WEIHRICH, H.: Management, Victoria Publishing : Praha, 1993. ISBN 80-85605-45-7.

[11] HITTMAR, S.: Management (in Slovak), EDIS : University of Zilina, 2006. ISBN 80-8070-558-5. 
[12] SOVIAR, J., VODAK, J.: Value Network as Part of New Trends in Communication, Communications - Scientific Letters of the University of Zilina, vol. 14, No. 2, 2012. ISSN 1335-4205.

[13] SOVIAR, J.: From Cooperation to Management - Cooperative Management, Habilitation thesis, Faculty of Management Science and Informatics : Zilina, 2012.

[14] CHILD, J., FAUlKNER, D., TALlMAN, S.: Cooperative Strategy. Managing Alliances, Networks, and Joint Ventures, Oxford University Press, 2005. ISBN 978-019-926625-8.

[15] FAULKNER, D. O.: International Strategic Alliances: Co-operating to Compete. Maidenhead : McGraw-Hill, 1995.

[16] Phoocharoon, P., CUYVERS, L., CHOMVILAILUK, R.: Cooperative Strategy to Strategic Competitiveness through International Joint Ventures between ASEAN and EU Companies, CAS Discussion paper, No. 33. Centre for ASEAN Studies, Centre for International Management and Development : Antwerp, 2001.

[17] VARMUS, M.: Comparison of Selected Concepts Strategies, Theory of Management - part 1, EDIS : University of Zilina, 2009. ISBN978-80-554-0147-8.

[18] STOFKOVA, K., STOFKOVA, J.: Research of Strategic Management Utilization for Support of Education Activities and Regions Development. EDULEARN11: $3^{\text {rd }}$ intern. conference on education and new learning technologies, Barcelona, 2011, 5036-5040. ISBN 978-84-615-0441-1.

[19] DONNELlY, J., H., GIBSON, J., L., IVANCEVICH, J., M.: Management, Praha : Grada Publishing, 1997. ISBN 80-7169-422-3.

[20] PAYNE, A.: Handbook of CRM: Achieving Excellence in Customer Management, Butterworth-Heinemann. 2005. ISBN 978-075066437-0.

[21] BLASKOVA, M.: Management and Developement of Human Potential, $1^{\text {st }}$ edition (in Slovak), Zilinska univerzita, 2003, 212 p. ISBN 80-8070-034-6. 